\title{
QUALIFICAÇÃO PARA A MODERNIZAÇÃO PORTUÁRIA NO PROGRAMA DE ENSINO PROFISSIONAL MARÍTIMO (PREPOM)
}

\author{
QUALIFICATION FOR PORT MODERNIZATION IN THE MARITIME PROFESSIONAL \\ EDUCATION PROGRAM (PREPOM)
}

\author{
CALIFICACIÓN PARA LA MODERNIZACIÓN PORTUARIA EN EL PROGRAMA DE \\ EDUCACIÓN PROFESIONAL MARÍTIMA (PREPOM)
}

\author{
Luceli Gomes da Silva \\ (PPGS/UFPR, Brasil) \\ Mario Lopes Amorim \\ (UTFPR, Brasil)
}

\section{do) https://doi.org/10.29404/rtps-v5i8.360}

RESUMO: este artigo tem por objetivo analisar a qualificação da força de trabalho portuária avulsa do porto de Paranaguá (PR), para a sua adequação aos novos processos tecnológicos do setor. Os trabalhadores portuários avulsos (TPAs) se veem impelidos a autenticar suas competências profissionais através das certificações dos cursos ofertados pelo Órgão Gestor de Mão de Obra (OGMO). A qualificação certificada passa a regular a força de trabalho avulsa, aumentando a procura por cursos do Programa do Ensino Profissional Marítimo (PREPOM) pelos TPAs. Utilizou-se de pesquisa documental, pesquisa de campo e de entrevistas semiestruturadas para se concluir que os TPAs incorporaram em seus próprios discursos a necessidade da qualificação, para atenderem às demandas e exigências da modernização portuária por um novo perfil de TPA, competente e multifuncional, com o fito de se manterem empregados.

Palavras-chave: Trabalhadores Portuários Avulsos, Educação para o Trabalho, Qualificação Profissional, Programa de Formação Profissional.

\begin{abstract}
: this article aims to analyze the qualification of the port laborforce of the port of Paranaguá (PR), for its adaptation to the new technological processes of the sector. Detached port workers (TPAs) are compelled to authenticate their professional skills through the certification of courses offered by the Laborforce Manager (OGMO). Certified qualification now regulates the single workforce, increasing demand for TPAs for the Maritime Professional Education Program (PREPOM). Documentary research, field research and semistructured interviews were used to conclude that the TPAs incorporated in their own discourses the need for qualification to meet the demands and requirements of port modernization for a new, competent and multifunctional TPA profile, in order to keep themselves employed.
\end{abstract}

Keywords: Dock Workers, Education for Work, Professional Qualification, Professional Education Program.
RESUMEN: este artículo tiene como objetivo analizar la calificación de la fuerza laboral portuaria del puerto de Paranaguá (PR), para su adaptación a los nuevos procesos tecnológicos del sector. Los trabajadores portuarios ocasionales (TPA) están obligados a autenticar sus habilidades profesionales a través de la certificación de los cursos ofrecidos por el Organismo de Gestión Laboral (OGMO). La calificación certificada ahora regula la fuerza laboral única, aumentando la demanda de TPA para el Programa de Educación Profesional Marítima (PREPOM). La investigación documental, la investigación de campo y las entrevistas semiestructuradas se utilizaron para concluir que los TPA incorporaron en sus propios discursos la necesidad de calificación, para satisfacer las demandas y demandas de modernización de puertos para un nuevo perfil de TPA competente y multifuncional, para mantenerse empleados.

Palabras Clave: Trabajadores Portuarios, Educación para el Trabajo, Calificación Profesional, Programa de Educación Profesional Marítima. 


\section{Introdução}

O presente artigo é fruto de pesquisa realizada no âmbito do Grupo de Estudos e Pesquisas em Trabalho, Educação e Tecnologia (GETET), vinculado ao Programa de PósGraduação em Tecnologia e Sociedade (PPGTE), da Universidade Tecnológica Federal do Paraná (UTFPR), e tem como escopo a investigação da qualificação profissional do Trabalhador Portuário Avulso (TPA), na nova regulação da gestão da força de trabalho avulsa no Porto de Paranaguá-PR, após a implantação das Leis dos Portos, a Lei $n^{\circ}$ 8.630/1993, e sua edição, a Lei $n^{\circ} 12.815 / 2013$ - ambas conhecidas como Leis de Modernização Portuária (BRASIL, 1993; 2013). A modernização dos métodos de manuseio e acondicionamento das cargas dos navios e a introdução das tecnologias logísticas de carregamento e descarregamento, que aumentam a produtividade e velocidade das operações portuárias, ensejaram uma qualificação diferenciada dos TPAs, ajustada às novas demandas de competências profissionais e multifuncionalidade.

Neste contexto, a gestão da força de trabalho avulsa passou a ser executada por uma instituição sem fins lucrativos, mas mantida pelas empresas operadoras no porto, o OGMO (Órgão Gestor de Mão-de-Obra), cabendo a este o papel legal de qualificar profissionalmente os TPAs para as novas funções das operações portuárias, o que resultou na alteração da qualificação, que passa a ser normatizada por meio da certificação dos cursos ofertados pelo OGMO, via convênio com a Marinha através do Programa do Ensino Profissional Marítimo (PREPOM). Sendo assim, o objetivo principal consiste em analisar a qualificação ofertada a partir da nova regulação da força de trabalho avulsa, considerando as relações diretas que se estabeleceram entre capital e trabalho após o controle patronal sobre a gestão da força de trabalho avulsa, e sobretudo os critérios impostos de qualificação para o TPA.

Para tanto, o estudo desenvolveu-se por meio de levantamento documental das normas que regem o PREPOM, e da legislação portuária, bem como de pesquisa de campo e de entrevistas semiestruturadas com trabalhadores portuários. A base teórica da pesquisa se assenta na noção de qualificação como relação social e seu deslocamento para a noção de competências, esta última oriunda do discurso empresarial, evidenciando materialidade ao conceito de empregabilidade e individualização do trabalhador, no contexto da flexibilização da organização e gestão do trabalho. Por fim, trata da conceituação de multifuncionalidade na reconfiguração dos processos de produção.

O texto estrutura-se em três seções. Inicialmente, são apresentados o Trabalhador Portuário Avulso e a natureza da sua qualificação, apoiada em sua aprendizagem empírica e mútua para o cotidiano do trabalho portuário, e as novas demandas de qualificação profissional advindas das Leis de Modernização Portuária. Em seguida, são investigados os cursos do Programa do Ensino Profissional Marítimo (PREPOM), tidos como necessários para os TPAs autenticarem suas competências profissionais através das certificações de tais cursos. Por fim, se buscará captar como se dá atualmente o processo de qualificação profissional dos TPAs. 


\section{Os TPAs e os novos requisitos de qualificação profissional decorrentes das Leis de Modernização Portuária}

O Trabalhador Portuário Avulso (TPA) é aquele trabalhador que participa da operação portuária, auxiliando no carregamento e descarregamento das cargas dos navios, e em locais situados na área de porto público organizado e em terminais privados. Segundo Queiróz e Geraldo (2015, p. 33), o TPA é caracterizado pelo serviço de "arrumação e retirada das mercadorias no convés e porões dos navios, como também pelo trabalho na faixa do cais". As atividades portuárias que estes trabalhadores avulsos realizam "é marcada pela diversidade em função do tipo de carga a ser transportada, acarretando inserções bastante distintas na composição da força de trabalho necessária para sua execução" (SARTI, 1981, p. 161).

Também podemos dizer que o termo "trabalho avulso" é caracterizado por ser de natureza intermitente, sazonal, esporádica. Ainda podemos conceituar o trabalhador avulso como aquele que presta serviço, sem vínculo empregatício, para várias empresas tomadoras de serviço, porém possuem os mesmos direitos trabalhistas dos celetistas por conta de contratos determinados, firmados ao cumprimento das jornadas de trabalho que realizam. São trabalhadores filiados a uma entidade sindical que os representam enquanto categorias.

A categoria se caracteriza por apresentar uma "cultura portuária" própria e universal (SILVA, 1995; DIÉGUEZ, 2007). As características da "cultura portuária" vão ao encontro da:

[...] natureza ocasional do trabalho; o serviço árduo e perigoso; o modelo de "cooperação simples" na execução das tarefas em turmas e a comunicação horizontal entre diversas categorias de trabalhadores; a falta de associação regular a um único patrão; os contatos frequentes com mercadorias, navios, marinheiros, ideias e experiências estrangeiras; a moradia próxima ao porto e a crença partilhada pelos portuários de que os "outros da sociedade" os consideram um grupo de "status baixo" (SILVA, 1995, p. 11-12).

Além da constituição da "cultura portuária" (SILVA, 2000), o que caracteriza os trabalhadores avulsos nos diversos portos é a divisão do trabalho entre as categorias dos trabalhadores e a função que cada um assume nas etapas de cada atividade portuária. $\mathrm{O}$ processo de trabalho portuário ficava a cargo dos próprios trabalhadores em cada porão, apoiado pela organização do trabalho estabelecido pela categoria. Segundo Sarti (1981, p. 161), o trabalhador portuário avulso tem uma função caracterizada como:

\footnotetext{
[...] trabalho não qualificado, mas que exige força física e habilidade no manejo da maquinaria: atividade do tipo intermitente, mas que requer disponibilidade da mão de obra que a qualquer momento pode ser convocada; local de trabalho que se distingue por ser o $\mathrm{X}$ da questão do comércio de exportação e importação.
}

Diéguez (2010, p. 1) afirma que o trabalho portuário é reconhecido como "um processo artesanal, onde a força física é requerida, tendo por imagem clássica, trabalhadores com sacas sobre as cabeças. Essa fase do processo de trabalho se estendeu durante anos nos 
portos". Neste contexto podemos distinguir duas fases do trabalho portuário avulso, uma antes da Lei dos Portos de 1993 e outra depois desta.

A fase anterior à lei portuária compreende aquela da organização sindical das categorias avulsas, que intermediavam a própria força de trabalho dos seus filiados. Era o chamado sistema de closep-shop (DIÉGUEZ, 2007), uma prática que não é exclusiva só dos portuários, mas ela se constituiu nessa categoria como maneira de garantirem o mercado de trabalho e sua manutenção associado ao sindicato. Cruz (1988, appud DIÉGUEZ, 2007, p. 64), ressalta a importância que o closed-shop tinha por exercer um controle sobre a entrada de novos membros no mercado de trabalho, restringindo este aos homens que realmente faziam da atividade portuária seu principal meio de sobrevivência, aliado à identidade profissional.

O disciplinamento legal para o gerenciamento da mão de obra avulsa seguia o modelo do aparelho do Estado por meio de um conjunto de normas legais, as quais regravam o trabalho portuário. Nesta primeira fase, pode-se dizer que a formação do trabalho portuário avulso foi marcada por uma organização convencional própria em torno dos sindicatos portuários de cada categoria ${ }^{1}$, a partir do chamado rodízio, ou melhor dizendo, da distribuição equitativa do trabalho entre os trabalhadores, através da intermediação da força de trabalho feita pelos sindicatos. Nesse contexto, as entidades sindicais representantes dos trabalhadores avulsos detinham certa autonomia e controle sobre a própria intermediação da força de trabalho avulsa, com alto poder de barganha (CARVALHO, 2005; DIÉGUEZ, 2007). Assim, anteriormente às Leis dos Portos, o processo de formação das categorias dos trabalhadores portuários avulsos constituiu-se através da natureza da qualificação no cotidiano do trabalho e apoiado na aprendizagem empírica e mútua entre os próprios trabalhadores. A noção de ofício para estas categorias era um componente central, não só na constituição da cultura do trabalho portuário, mas como instrumento de militância. A militância era um elemento para obtenção de melhores condições de salários e reserva do mercado de trabalho, mobilizada no "próprio exercício diário da profissão como forma de distinção e especialização do trabalhador" (DIÉGUEZ, 2014, p. 278).

O processo de trabalho portuário era um processo do tipo artesanal, que solicitava destrezas, habilidades e dispêndio físico, apoiado na noção de ofício. Tratava-se, portanto, de uma força de trabalho de natureza braçal, caracterizada pelo aspecto intermitente e ocasional do trabalho, cuja função imprimia um saber-fazer próprio e específico do ofício.

Portanto, os componentes da prática tradicional da categoria dos trabalhadores avulsos foram bastante expressivos, fundamentais para o reconhecimento profissional das categorias avulsas através da organização sindical, sob a qual tinha o controle do mercado de trabalho e da intermediação da força de trabalho. Pode-se concluir que a formação do

\footnotetext{
${ }^{1}$ As categorias do trabalho portuário são: estivadores, bloco, vigias, consertadores, conferentes, capatazes e arrumadores. Para mais informações a respeito das mesmas (Cf.: SAAD, 2004).
} 
trabalhador portuário podia ser considerada como uma qualificação para o trabalho enquanto relação social, de acordo com Pierre Naville $(1956)^{2}$. Este autor,

[...] não concebe a qualificação apenas do prisma da técnica e do conteúdo do trabalho (ainda que os considere), mas antes como sendo um processo e um produto social, que decorre, por um lado, da relação e das negociações tensas entre capital e trabalho e, por outro, de fatores socioculturais que influenciam o julgamento e a classificação que a sociedade faz sobre os indivíduos (TARTUCE, 2004a, p. 362).

Para tanto, compreende que a qualificação não é um conceito acabado em si mesmo, ou um termo restrito, mas refere-se ao conceito amplo da qualificação, que se articula em diferentes dimensões da vida social, econômica, política e cultural. Nessa perspectiva, a qualificação não deve ser considerada um fenômeno abstrato, mas reconhecida na relação social dos sujeitos, situados historicamente no tempo e espaço. Além de tudo, podemos entender que a qualificação se torna uma noção articuladora de diferentes elementos no contexto das relações sociais de trabalho. Neste sentido, ao pensar a qualificação, Naville (1956) procurou mostrá-la na relação com o sistema social, principalmente teorizando-a na divisão social do trabalho, na automação e no sistema salarial.

Contudo, no começo da década de 1990, com a inserção de um novo modelo produtivo portuário, esta organização sindical do trabalho avulso arraigada na cultura portuária e na noção do ofício, que durante muitas décadas foi apoiada num certo tipo de qualificação constituída na natureza do trabalho portuário no seu cotidiano foi modificada, enfraquecendo o poder dos trabalhadores (DIÉGUEZ, 2014).

Nos anos 1990, a agenda da modernização portuária ganhou notoriedade na sociedade brasileira. A modernização dos portos entrou na pauta do discurso nesta década sob o argumento de que este modal estaria com a infraestrutura defasada e sucateada e, por conta da baixa produtividade, prejudicaria a inserção do país na nova lógica neoliberal da globalização dos mercados exportadores e importadores. A reforma portuária era um consenso dos empresários do segmento, e a pressão exercida por estes acelerou ainda mais a pauta da modernização nos portos brasileiros. Neste contexto, entrou em tramitação no Congresso Nacional o Projeto de Lei 08/1991, considerado polêmico, pois não contemplava os interesses da maior parte dos envolvidos que eram das categorias dos trabalhadores portuários avulsos (DIÉGUEZ, 2007).

Este período foi de grande resistência e de greves nacionais por parte dos sindicatos e federações dos trabalhadores portuários. Segundo Diéguez (2007, p. 52),

Foram dois anos de debates intensos e muitas cessões por parte de todos envolvidos no
processo. Por parte dos trabalhadores, a greve foi um recurso muito utilizado. As paralisações
nos portos brasileiros eram constantes. O seu uso funcionava como forma de confirmação da
solidariedade e coesão do movimento sindical, além de levar o debate para a sociedade civil.
Em 1992, houve uma greve portuária nacional, que durou sete dias e visava pressionar os
deputados para manterem os direitos dos trabalhadores, principalmente o monopólio

2 Pierre Naville (1903-1993), sociólogo francês, considerado fundador da Sociologia do Trabalho na França, cujos estudos analisam as relações entre as novas tecnologias e seus efeitos sociais. 
sindical da organização da mão-de-obra. Do lado dos empresários os argumentos que os portos eram muito caros e que a mão-de-obra era o grande peso dos preços praticados nos portos, impossibilitando uma expansão do comércio exterior, foram bastante utilizados.

Após intensas disputas no Congresso Nacional entre os grupos de interesses e sob forte influência de lobbys e pressão da mídia (DIÉGUEZ, 2007), os congressistas aprovaram a Lei de Modernização Portuária, a Lei n 8.630/1993 (BRASIL, 1993). O novo ordenamento jurídico da modernização dos portos trouxe consigo um novo regramento para as relações do trabalho avulso, alterando profundamente a configuração do processo de trabalho, buscando não só modernizar toda a infraestrutura logística portuária do porto organizado, em relação à concessão e exploração dos portos públicos brasileiros, mas também imprimindo novas condições da gestão e intermediação da força de trabalho portuária.

Se antes a organização e a intermediação da mão de obra do trabalho avulso eram vinculadas aos sindicatos das categorias dos TPAs, após a promulgação da Lei dos Portos passa a ser executada por uma entidade de caráter patronal, sem fins lucrativos e de interesse público, mas mantida pela iniciativa privada, chamada Órgão Gestor da Mão de Obra do Trabalho Portuário (OGMO). O OGMO foi criado com a finalidade de regular, escalar, fiscalizar e intermediar a mão de obra avulsa, o que alterou profundamente a relação capital-trabalho, pois consistiu em extinguir o monopólio sindical dos TPAs, visto pelo governo e empresários do segmento portuário como o principal obstáculo para as alterações requisitadas para o referido setor (DIÉGUEZ, 2007).

A lei cria a figura do operador portuário (designação concedida às empresas que exploram as operações portuárias) e reduz todas as categorias dos trabalhadores avulsos a uma única nomenclatura, qual seja, Trabalhadores Portuários Avulsos (TPAs) (PINTO; FLEURY, 2004 e NETO; VENTILARI, 2004).

Em Paranaguá, o Órgão de Gestão da Mão-de-Obra do Trabalho Portuário Avulso do Porto Organizado de Paranaguá (OGMO/Paranaguá) foi criado em 26 de setembro de 1995, como a instituição responsável pela qualificação profissional dos TPAs da região litorânea do Paraná. Para fazer cumprir as determinações da Lei dos Portos em relação à atribuição na qualificação profissional dos TPAs, em 1998, o OGMO de Paranaguá passou a celebrar convênios administrativos anualmente com a Diretoria de Portos e Costas (DPC), órgão vinculado à Marinha do Brasil por meio da Capitania dos Portos da região, para ofertar cursos de formação profissional do PREPOM.

Muito embora as categorias dos TPAs mantivessem a reserva do mercado de trabalho e a exclusividade sobre o serviço portuário (NETO; VENTILARI, 2004), o desafio estava posto em relação a uma maior qualificação profissional destes trabalhadores para se adequarem aos novos métodos de manuseio e acondicionamento das cargas dos navios e tecnologias logísticas da automação das operações portuárias. A fase após a implantação da lei portuária de 1993 trouxe consigo a discussão da qualificação profissional dos TPAs no âmbito do governo, segmentos empresariais, sindicatos e trabalhadores, antes ignorada no antigo contexto da organização do trabalho portuário avulso. Não é exagero dizer que a discussão da qualificação profissional do TPA não nasceu por iniciativas benevolentes, mas 
por conta dos paradigmas das noções de competências, empregabilidade, multifuncionalidade e de maior escolaridade básica do novo perfil de trabalhador, que emergiram através da difusão global dos novos modelos produtivos de automação flexível do trabalho.

No que se refere à multifuncionalidade, a Lei n 8.630/1993 (BRASIL, 1993) estabelece que o TPA deve buscar a multifuncionalidade para se adequar aos modernos processos logísticos da operação portuária, o que enseja um novo perfil de TPA, que deve se tornar generalista em detrimento da especificidade do oficio de cada categoria sindical, portanto não mais vinculado à noção tradicional do ofício, mas apto para todas as atividades portuárias (NETO; VENTILARI, 2004). Em suma, o termo "multifuncionalidade portuária", empregado no contexto da modernização dos portos, diz respeito ao treinamento multifuncional, isto é, aquele que permite a habilitação necessária para o TPA exercer as múltiplas funções das operações portuárias.

\section{Os cursos do Programa do Ensino Profissional Marítimo (PREPOM), no porto de Paranaguá}

O Programa do Ensino Profissional Marítimo (PREPOM), correlato aos portuários, é um programa elaborado anualmente pela Superintendência do Ensino Profissional Marítimo da DPC, que visa estabelecer critérios técnicos, bem como regular normas pedagógicas e operacionais para o planejamento e execução da programação anual dos cursos do sistema de Ensino Profissional Marítimo para os TPAs, a fim de orientar e divulgar aos Órgãos de Execução (as Capitanias dos Portos) e aos Órgãos Conveniados (OGMO) as informações específicas sobre os estágios de execução dos cursos contidos no PREPOM para determinado ano corrente.

O PREPOM para portuários pode ser caracterizado como um programa operacional normativo de formação técnica e profissional composto por cursos sequenciais ${ }^{3}$, superiores e de pós-graduação, que visam propiciar uma modalidade de ensino específica não conferida por outras, na qual propõe não só capacitar profissionalmente os TPAs vinculados ao OGMO, mas também aperfeiçoar a comunidade portuária que exerce funções administrativas, técnicas ou operacionais dos serviços portuários, agências de navegação, empresas que atuam em terminais privativos, entre outros.

As normas que regem o PREPOM e que norteiam o Sistema do Ensino Profissional Marítimo (SEPM) foram influenciados por alguns aspectos, sobretudo aqueles que dizem modernizar os portos brasileiros. Sendo assim:

\footnotetext{
${ }^{3}$ Os cursos sequenciais, de acordo com o Art. 44 da LDBEN, alterados pela redação da Lei n¹1.632, de 2007, consistem numa modalidade de ensino na qual o aluno, após ter concluído o ensino médio, poderá ampliar seus conhecimentos ou sua qualificação profissional (BRASIL, 1996; 2007).
} 


\begin{abstract}
Estas normas são influenciadas por diversos fatores, principalmente os que condicionaram a modernização portuária por força da Lei 8.630/93 que, não só alterou profundamente o regime jurídico dos portos como, também, a gestão de mão-de-obra da orla portuária, sendo, por essa razão, um instrumento eminentemente dinâmico. Assim, caberá ao Departamento de Ensino de Portuários acompanhar a evolução daqueles fatores, propondo as revisões ou atualizações necessárias para que a Superintendência do Ensino Profissional Marítimo da Diretoria de Portos e Costas (DPC) julgue a oportunidade de executá-las. Porém, as normas estabelecidas foram redigidas de modo a assegurar uma relativa estabilidade no tempo. Com essa intenção, foram incluídas as metas do ensino de portuários e as ações recomendadas decorrentes, de modo a proporcionar aos integrantes do Sistema uma ampla visão dos propósitos da DPC no gerenciamento da habilitação e da qualificação dos Trabalhadores Portuários, seja na condição de avulsos (TPA) ou com vínculo permanente (TP) (DPC, 2008, p. 8).
\end{abstract}

Nesse contexto, O PREPOM e todo o SEPM tiveram alterações significativas no que tange à reformulação da sua visão de qualificação profissional para o segmento portuário. Influenciado pela modernização dos portos e por todas as modificações da infraestrutura logística apoiadas por inovações tecnológicas e organizacionais, além dos novos parâmetros técnicos dos métodos de manuseio e acondicionamento das cargas das operações portuárias - que vigorou de forma mais acentuada nos anos de 1990 nos portos do país -, a Superintendência do Ensino Profissional da DPC, por força da Lei dos Portos de 1993, procurou se ajustar e redefinir novas atualizações a partir da adição de um novo Órgão Conveniado componente da estrutura básica do SEPM, o OGMO.

Cabe ao OGMO a seleção e a contratação dos recursos humanos para o ensino de portuários tais como as instituições, professores e instrutores que realizarão a formação profissional dos TPAs, mantendo atualizado um cadastro de professores e instrutores recrutáveis (DPC, 2012). A maioria dos professores/instrutores cadastrados pelo OGMO são os próprios TPAs concluintes do curso de Instrutoria, chamado Curso de Técnica de Ensino (CTE) do SEPM, e que obtiveram a certificação necessária para ministrar a formação profissional para o ensino dos portuários. Em relação às diretrizes dos recursos instrucionais relativos aos materiais didáticos de apoio ao ensino, a DPC é a responsável pela elaboração deles, processo de modernização dos portos, e sua disponibilidade de acesso é restrita aos encarregados e coordenadores responsáveis junto ao OGMO pela execução dos cursos do PREPOM. No que diz respeito â infraestrutura física, instalações e todos os recursos materiais, tais como aluguel de salas de aula, pátios, armazéns, simuladores, equipamentos de operação portuária, bem como outros que se façam necessários para o desenvolvimento dos cursos, o OGMO ou o Órgão de Execução são encarregados do provimento e fornecimento desses recursos, mediante celebração de acordo administrativo entre si, na modalidade convênio (DPC, 2012).

Para fins da materialização do referido acordo administrativo, na modalidade convênio, cabe ao OGMO, inicialmente, realizar um levantamento da demanda local referente às necessidades de qualificação profissional dos TPAs para o planejamento, oferta e execução dos cursos para o ano subsequente. Essa apuração é feita através de consulta da comunidade portuária envolvida, principalmente de todos os Sindicatos dos Trabalhadores Portuários Avulsos e dos Operadores Portuários da região. 
A proposta dos cursos do PREPOM se apoia no processo contínuo e sistemático de transmissão dos conhecimentos e informações que se julguem necessárias à preparação para a atividade profissional dos TPAs.

\begin{abstract}
Enquanto processo deve ser contínuo, progressivo e sistemático a fim de possibilitar a realização da aprendizagem de técnicas, atitudes e habilidades pelos alunos, mediante a ação didática de professores/instrutores. Nesse contexto, os cursos são fruto de pesquisas e análises sobre o que é preciso ensinar, de modo a garantir que todas as ações venham a convergir no sentido de prover a capacitação necessária para o desempenho das diferentes tarefas inerentes à atividade portuária (DPC, 2012, p. 13).
\end{abstract}

Baseado no conceito de "processo contínuo de aprendizagem", os cursos podem incluir regularmente "estágios com as operadoras portuárias ou prática com simuladores, visando dar ao aluno as habilidades necessárias ao exercício da função" (DPC, 2012, p.13). Pode-se observar que se incorpora uma nova ótica de formação profissional a partir do processo de modernização dos portos, que anteriormente a este era direcionado apenas para a aplicação do ensino teórico. Nessa perspectiva atual de ensino-aprendizagem, a proposta adotada é a integração da teoria e da prática como formas de dinamização didática. Os termos habilitação, qualificação e treinamento são incluídos como conceitos dos cursos com a finalidade de conferir ao TPA a capacitação necessária ao exercício profissional das atividades referentes à operação portuária. Decorre disso que, para contribuir com o treinamento da mão de obra avulsa, a aplicação da parte prática dos cursos é voltada à fixação do conteúdo teórico transmitido em sala de aula (DPC, 2012; 2017).

A DPC elaborou, como proposta dos cursos, um instrumento que pode ser aplicado pelo OGMO para mensurar a efetivação do treinamento profissional do TPA, bem como o nível de satisfação que a comunidade portuária tem com a utilização da mão de obra avulsa, tomando por base o estudo das tarefas críticas das atividades que compõem o trabalho portuário, como por exemplo, a habilidade do TPA para operar determinado equipamento de movimentação de cargas, a fim de "verificar a efetividade da relação custo/benefício dos cursos de qualificação e propor medidas adequadas ao seu aprimoramento" (DPC, 2012, p. 31).

De acordo com o Quadro 1, percebe-se que os cursos seguem uma seriação e progressão. Para elevar o nível de profissionalismo do trabalhador portuário avulso, isto é o conjunto de capacitação e competências que compõem o profissional naquilo que rege as suas atividades e seu campo de trabalho portuário, como pré-requisito precisará concluir os cursos da classificação básica, e assim sucessivamente, até alcançar a conclusão dos cursos expeditos e de atualização. Para tal conclusão, os trabalhadores devem cumprir todos os requisitos referentes à avaliação teórica, nota mínima exigida, cumprimento da carga horária estabelecida, revisão dos conteúdos das disciplinas, e se houver avaliação prática para operação de equipamento, deverá cumprir as horas-aula direcionadas exclusivamente para a prática em simuladores ou no próprio equipamento, a fim de avaliar se o TPA-aluno conseguiu absorver os conceitos operacionais propostos no curso, e a capacidade de sua aplicação adequada para operacionalização com segurança e destreza. 
Por fim, será realizada a prova final, e se obtiver aproveitamento será concedido o certificado do curso, o qual é chancelado tanto pelo OGMO como pela DPC.

\section{Quadro 1: Cursos ofertados pelo PREPOM}

\begin{tabular}{|c|c|}
\hline Cursos & Descrição \\
\hline Básicos de Formação & $\begin{array}{l}\text { Formação Básica dos TPAs para as funções, conforme peculiaridades de cada } \\
\text { categoria de trabalhadores e sindicatos avulsos }\end{array}$ \\
\hline Aperfeiçoamento & $\begin{array}{l}\text { Ampliação dos conhecimentos necessários ao desempenho dos cargos e ao } \\
\text { exercício das funções peculiares às atividades portuárias }\end{array}$ \\
\hline Expeditos & Habilitação técnico-profissional para o exercício de atividades com equipamentos \\
\hline Especiais & $\begin{array}{l}\text { Preparação dos TPAs para o exercício de atividades que exijam qualificações } \\
\text { específicas não conferidas por cursos de outras modalidades }\end{array}$ \\
\hline Avançados & $\begin{array}{l}\text { Preparação dos portuários para o exercício de cargos e funções na administração e } \\
\text { gerência técnica de órgãos e empresas vinculadas ao transporte marítimo }\end{array}$ \\
\hline Atualização & $\begin{array}{l}\text { Provimento de conhecimentos necessários aos TPAs para se adequarem às } \\
\text { exigências do avanço tecnológico }\end{array}$ \\
\hline
\end{tabular}

Fonte: Elaboração própria (2019)

Os cursos do PREPOM seguem o planejamento anual realizado pelo OGMO, e dentro deste consta a solicitação do custeio dos cursos que são encaminhados à Capitania dos Portos que, por sua vez, terá por base a autorização da DPC, de acordo com os critérios normativos do SEPM e financeiros do Fundo de Desenvolvimento do Ensino Profissional Marítimo (FDEPM). O planejamento dos cursos PREPOM tem por base a demanda de cada porto, no que se refere às características das cargas movimentadas, tipos de navios que normalmente atracam e a especificidade das atividades realizadas e dos equipamentos das operações portuárias.

Portanto, para fazer frente aos requisitos de qualificação do mercado de trabalho local, predomina a concepção de que o TPA deverá cumprir o itinerário formativo do PREPOM para se atualizar constantemente em relação aos modernos processos de movimentação das cargas do Porto de Paranaguá.

\section{A pesquisa empírica}

A pesquisa com os TPAs se deu pela observação indireta, isto é, por um procedimento que visa captar dados e informações obtidas informalmente através de conversas e perguntas relativas ao trabalho portuário local, realizadas pela pesquisadora com pessoas- 
chave, registrando-as em caderno de campo. Para tanto, se fez necessária a aproximação do local de trabalho destes trabalhadores, pois assim foi possível obter uma visão ampliada no sentido de buscar a totalidade da realidade do objeto de pesquisa.

Também se optou pela entrevista semiestruturada com duas categorias de trabalhadores portuários avulsos, a estiva ${ }^{4}$ e o bloco ${ }^{5}$. A escolha de tais categorias se justifica por conta de a primeira ser a maior categoria de TPAs de Paranaguá; além disso, verificou-se que grande parte destes trabalhadores estivadores realizam os cursos assiduamente e possuem qualificação profissional especializada para os equipamentos de movimentação das cargas. A segunda categoria é por conta de ser, atualmente, um sindicato de trabalhadores multifuncionais, e que fazem os cursos periodicamente quando abrem vagas para capacitação da multifunção. O sindicato do bloco foi um entre os sindicatos das categorias dos TPAs que perderam postos de trabalho, e encontram na multifunção a oportunidade de se manterem no mercado de trabalho portuário local, através da qualificação dos cursos do PREPOM portuário, ofertados pelo OGMO de Paranaguá.

Dentre as pessoas-chave para a realização das entrevistas, elencamos um representante sindical do Sindicato da Estiva de Paranaguá (SINDESTIVA), e mais um representante sindical do Sindicato do Bloco de Paranaguá, dois instrutores/professores dos cursos do PREPOM junto ao OGMO de Paranaguá, os quais são também estivadores registrados e na ativa, seis trabalhadores portuários avulsos de base, sendo quatro estivadores e dois do bloco, além do coordenador responsável pelos cursos do OGMO de Paranaguá. As entrevistas foram gravadas, com permissão dos referidos entrevistados, e posteriormente transcritas e analisadas, com o objetivo de verificar as concepções dos atores em relação às atividades de formação profissional do PREPOM.

\section{O processo de qualificação profissional dos TPAs do porto de Paranaguá}

A Lei $n^{\circ} 8.630 / 1993$ atribui ao OGMO a competência para qualificar profissionalmente - TPA e adequá-lo aos modernos processos de movimentação de carga e dos equipamentos logísticos portuários (BRASIL, 1993). Anteriormente à Lei dos Portos, a prerrogativa da formação profissional dos trabalhadores portuários avulsos civis, embora de forma tímida e pouco abrangente, já era demandada pela DPC por meio da Capitania dos Portos, a qual tem a jurisprudência nas questões relativas ao âmbito portuário, como

\footnotetext{
${ }^{4}$ Estiva: a atividade de movimentação de mercadorias nos conveses ou nos porões das embarcações principais ou auxiliares, bem como o carregamento e a descarga das mesmas, quando realizados com equipamentos de bordo (BRASIL, 1993).

${ }^{5}$ Bloco: a atividade de limpeza e conservação de embarcações mercantes e de seus tanques, incluindo batimento de ferrugem, pintura, reparos de pequena monta e serviços correlatos (BRASIL, 1993).
} 
visto na seção anterior. Antes do OGMO assumir tal atribuição sobre a capacitação do TPA, já existia toda uma estrutura normativa do ensino profissional marítimo formalizada. A partir da função assumida do OGMO, de Órgão Conveniado do SEPM, coube ao mesmo a responsabilidade de ofertar cursos para promover a habilitação e a qualificação do trabalhador portuário avulso de Paranaguá.

É nesse contexto que em 1998 o OGMO de Paranaguá iniciou suas atividades formativas direcionadas para os TPAs da região, por meio da celebração do convênio com a DPC. A partir disso, foram estabelecidas as metas do ensino e as ações recomendadas, de modo a assegurar os conceitos e os modelos destinados a orientar o planejamento, gerenciamento e a aplicação dos cursos PREPOM para a qualificação dos TPAs (DPC, 2008).

Se antes, o ensino para portuários era pouco abrangente e restrito para os TPAs da localidade, sem grandes exigências de certificação extensivas para a habilitação ao trabalho, com a nova gestão da mão de obra do trabalho portuário avulso, a situação apontou para outra, completamente diversa da anteriormente adotada pelos TPAs no que diz respeito ao tipo de formação para e no trabalho portuário. Esta formação apoiada na "cultura portuária", isto é, na aprendizagem empírica do ofício ensinada através da experiência e da prática da estivagem e desestivagem a bordo do navio, e na colaboração mútua entre os trabalhadores da capatazia em terra, paulatinamente está dando lugar para as cerificações dos cursos. Ou seja, a qualificação tácita, enraizada na prática dos TPAs, vem sendo suprimida por um conjunto de competências requisitado para os novos padrões produtivos dos novos métodos e técnicas de manuseio e acondicionamento das cargas dos porões e conveses dos navios, e do investimento privado dos novos equipamentos logísticos tecnológicos no porto de Paranaguá.

Dentre as dificuldades encontradas inicialmente pelo OGMO de Paranaguá para a implantação dos cursos PREPOM, destaca-se o pré-requisito de educação formal para a realização das matrículas nos cursos. No entanto, a realidade encontrada mostrava que a maioria dos trabalhadores sequer tinha o grau mínimo de escolaridade exigido 6 .

Visando as adequações necessárias dos TPAs para tais exigências do PREPOM, a primeira ação do OGMO, juntamente com o Sindicato dos Estivadores dos Portos de Paranaguá e Pontal do Paraná (SINDESTIVA) ${ }^{7}$, foi a realização do convênio com o governo estadual para oportunizar acesso à Educação de Jovens e Adultos (EJA). Através dessas medidas educativas, do ano de 1998 até 2001 foram formados cerca de 400 trabalhadores nos cursos supletivos do ensino fundamental e médio ofertados pelo OGMO, possibilitando

\footnotetext{
${ }^{6}$ Informações coletados em pesquisa de campo no OGMO de Paranaguá, em dezembro de 2017.

7 As aulas da modalidade de Ensino de Jovens e Adultos (EJA) para os TPAs foram realizadas no Centro de Treinamento Portuário (CTP), estrutura física construída e cedida pelo Sindicato dos Estivadores dos Portos de Paranaguá e Pontal do Paraná (SINDESTIVA) na época.
} 
a adesão de um número maior de TPAs aos cursos do PREPOM (TRABALHADORES, 2000, p. 5).

A primeira etapa da implantação dos cursos do PREPOM pelo OGMO/PR viabilizou, num primeiro momento, fornecer e ampliar o acesso para a conclusão da escolaridade básica, a fim de que os TPAs tivessem os requisitos exigidos para a realização das matrículas nos cursos, e ter as ferramentas necessárias (escrita e leitura) para a compreensão da parte teórica do ensino transmitido em sala de aula.

Em uma segunda etapa, o OGMO/PR promoveu vagas no Curso de Técnicas de Ensino (CTE), na modalidade Especiais, direcionadas aos TPAs interessados em se especializar na formação de professores/instrutores para ministrar os cursos do PREPOM. Foram ações que formaram TPAs/instrutores altamente especializados nas operações com equipamentos tecnológicos de movimentação de cargas, o que viabilizou um ensinoaprendizagem maior para os alunos-trabalhadores na prática dos seus estágios obrigatórios, realizados na operação dos equipamentos importados da Europa. Nesse contexto, o OGMO/PR promoveu intercâmbio dos TPAs/instrutores do PREPOM para o aprendizado nos equipamentos de ponta dos portos da Europa.

Atendendo a necessidade de mão de obra especializada para operar os novos equipamentos de movimentação de cargas empregados por meio de investimentos da iniciativa privada no Porto de Paranaguá, observa-se, nesse contexto, que o OGMO/PR procurou atingir, nesse primeiro momento da implantação do PREPOM, os objetivos das demandas locais referentes aos novos processos produtivos do trabalho portuário.

Ademais, emergiu a lógica de que a certificação profissional ofertada pelos cursos do PREPOM seria uma maneira do TPA se manter no mercado de trabalho, garantindo a oportunidade deste se habilitar nas funções das operações portuárias com equipamentos, e possivelmente obter ganhos salariais maiores. Houve, nesse sentido, um crescimento nas demandas por mais vagas nos cursos requisitadas pelos próprios TPAs, a fim de cumprir o itinerário formativo da lista de treinamento da classificação do PREPOM, sendo este a carga horária dos cursos da formação básica (obrigatório para todos os TPAs que têm a escolaridade mínima ou fundamental I); as cargas horárias dos cursos de aperfeiçoamento; os especiais (optativos); e principalmente os cursos expeditos, que habilitam para o exercício das atividades para operação de equipamentos de movimentação de contêineres, estes para os TPAs que têm o ensino médio completo.

Através da chamada eletrônica, implantada em 2007, e a atual - via web - foi estabelecido um controle mais efetivo das listas $^{8}$ contidas no sistema das diversas funções

\footnotetext{
8 A lista diz respeito ao agrupamento dos TPAs certificados ou capacitados para exercer determinada função da operação portuária, de acordo com o critério dos cursos realizados, dividindo as listas entre funções que demandam maiores competências e conhecimentos para executar funções mais sofisticadas de excelência com equipamentos de ponta, e outras que demandam serviços básicos com as certificações apenas dos cursos básicos.
} 
exercidas pelo TPA. Ou seja, há várias listas específicas para as funções da operação portuária. Sendo assim, existe um controle maior sobre a formação profissional e a habilitação do TPA, das diversas funções que exercem nas operações portuárias que são organizadas através das listas.

Destaca-se, sobretudo, que as exigências das certificações dos cursos para o trabalho portuário não se dão consensualmente, elas são compulsórias e impositivas através de um conjunto de ações fiscalizatórios e notificadoras. Dentre elas, destaca-se a Auditoria Fiscal do Trabalho do Paraná, constituída pelo Grupo Móvel da Fiscalização do Trabalho Portuário, da Delegacia Regional do Trabalho do Paraná (DRT/PR). Este Grupo fiscaliza todas as operações portuárias do Porto de Paranaguá no que diz respeito às competências e certificações dos cursos, exigidas para o TPA operar um determinado equipamento do porto ou função. Estes fatores "impelem" ou "forçam" o TPA para que este se qualifique e se atualize constantemente para as funções portuárias.

Quanto aos recursos provenientes do Fundo de Desenvolvimento do Ensino Profissional Marítimo (FDEPM) para a realização dos cursos em Paranaguá, estes sofrem contingenciamento e são considerados insuficientes para atender a demanda necessária, pois a totalidade dos recursos recolhidos não é repassada integralmente. Seguindo a tendência da falta de investimentos para a educação de qualidade no Brasil, o ensino para portuários também sofre o não-repasse devido, portanto, poucos cursos em Paranaguá são autorizados pela DPC. Ademais, a verba que o governo federal repassa para cursos e treinamentos fica sob a "responsabilidade da Marinha, através da Diretoria de Portos e Costas, gestora do Fundo de Desenvolvimento do Ensino Profissional Marítimo" (PAUL; FREDDO, 2009, p. 162-163).

Outra questão diz respeito à lentidão do sistema para a atualização do material didático-pedagógico, as metodologias e técnicas de ensino dos cursos PREPOM, as quais não correspondem com a velocidade da evolução tecnológica dos equipamentos na logística portuária. Muitos conteúdos contidos nas apostilas do ensino não agregam para a formação do TPA, ou seja, são conteúdos que se repetem nas classificações dos cursos básicos e dos expeditos. Há uma morosidade e burocracia do sistema para atualizar o PREPOM.

O PREPOM não consegue atingir seus objetivos de ensino por estar distante da realidade da demanda da logística portuária local. A qualificação ofertada não corresponde com a prática e realidade do trabalho portuário, e a falta dela dificulta a integração do TPA nas listas das escalas das atividades mais complexas.

A Lei dos Portos preconizou todo um controle do TPA através da intermediação da gestão da mão de obra e da oferta da formação profissional e treinamento multifuncional, inserindo um novo agente patronal - o OGMO -, mas não transferiu totalmente o controle da gestão do ensino para os portuários, ficando a cargo da DPC, órgão vinculado à Marinha, e do Estado. Estas contradições e limitações expostas têm gerado um campo de força e tensão entre os atores locais (Capitania dos Portos, OGMO/PR, Operadores Portuários, TPAs e Sindicatos Portuários) envolvidos com o processo da qualificação profissional do 
TPA do Porto de Paranaguá. Deste modo, concordamos com Fidalgo (1999), ao apontar que a implementação destas propostas de formação profissional estaria deixando de ser responsabilidade do Estado, para situar-se nas relações da negociação coletiva entre patronato e trabalhadores. É sem dúvida, um processo que "eleva a importância da formação da capacidade de trabalho, ela se torna ainda mais estratégica para o controle da mão-de-obra" (FIDALGO, 1999, p. 21).

Na perspectiva dos trabalhadores, a pesquisa empírica realizada com os trabalhadores apontou para quatro categorias de análise que possibilitaram expressar as diferentes visões que permeiam a questão que assumiu atualmente a qualificação do trabalhador portuário avulso. São elas a importância da qualificação tácita; a empregabilidade dos TPAs; a importância dos cursos do PREPOM para a qualificação dos TPAs; e a caracterização do trabalho portuário na atual regulação da gestão da força de trabalho avulsa.

A qualificação tácita é algo intrínseco ao TPA, por conta da própria especificidade da atividade que o trabalhador avulso realiza, é uma qualificação apoiada na experiência e no métier do cotidiano do trabalho portuário. É um conhecimento único que estas categorias avulsas trazem consigo e que ainda é repassado para os companheiros de trabalho na prática profissional. Embora a noção da certificação por competências tenha emergido como condicionante regulador da gestão da força de trabalho para estes TPAs realizarem suas atividades profissionais, o que dá a sensação do deslocamento da noção de qualificação para a noção de competências (TARTUCE, 2002; 2004b; RAMOS, 2006), tal deslocamento de noções pode ser incorporado na prática profissional, pois os trabalhadores sabem que hoje precisam seguir a padronização profissional das operações portuárias para executar suas funções, mas estas não se sobressaem sobre as qualificações tácitas, que ainda permanecem válidas.

A lógica da empregabilidade portuária se insere no que diz respeito à relação diretamente proporcional entre maior qualificação e maior chance de trabalho, que resulta no maior ganho salarial, decorrente de uma maior produtividade. Na visão dos TPAs, a empregabilidade portuária resulta de uma maior qualificação e treinamento para que possam se sobressair no mercado de trabalho.

Em relação à importância dos cursos do PREPOM para a qualificação dos TPAs, podese afirmar que a padronização profissional e técnica das operações portuárias foi um dos fatores para que os TPAs buscassem a certificação profissional dos cursos, e além disso, para este trabalhador ter progressão profissional, teria que realizar diversos cursos. No entanto, embora o OGMO assumisse os cursos de qualificação profissional dos TPAs, as condições didáticas dos materiais das apostilas dos cursos, de acordo com os trabalhadores pesquisados, não eram suficientes, por estarem desatualizadas e precisarem de uma reformulação. Embora haja uma diretriz didática do material, esta é insuficiente, e não seria exagero dizer que os instrutores dos cursos, que são TPAs, reelaboram esse material, de acordo com a necessidade de suas categorias. Nesse âmbito, destaca-se também a multifunção, isto é, a oferta de cursos pelo PREPOM para trabalhadores cujas categorias 
perderam mercado de trabalho devido à adoção de inovações tecnológicas, para se qualificarem para outras funções do trabalho portuário.

Atualmente, os próprios sindicatos negociam o quantitativo de vagas para os Terminais Privados. É uma nova realidade para o trabalho avulso, pois a vinculação tornouse um meio do próprio TPA não perder espaço no mercado de trabalho e obter um ganho salarial maior. A maior especialização profissional seria o requisito para este TPA se candidatar à vaga ofertada pela empresa privada das operadoras portuárias. A associação que se faz neste tipo de relação é proporcional à lógica da produtividade, ligada a maior qualificação do trabalhador. Pode ser associado também ao que Friedmann (1964) tratou em relação à qualificação do conteúdo do trabalho, aquela que se dá entre os saberes necessários para o posto de trabalho e o nível maior de formação.

A regulamentação da negociação coletiva trazida pela legislação portuária, entre sindicatos dos trabalhadores e sindicato patronal, é um fato no porto de Paranaguá. A estratégia coletiva agora é a negociação para manter-se no mercado de trabalho. Hoje negocia-se remuneração das fainas ${ }^{9}$, salário-produção do TPA, e a reivindicação de mais cursos de qualificação para os TPAs.

Outro fato diz respeito à diminuição drástica do número de fainas, e isso gera, consequentemente, a diminuição de equipes e redução dos postos de trabalho por conta da automação das operações portuárias. Observa-se, após a regulação da gestão da mão de obra, que as competências certificadas dos cursos adquiriram uma dimensão que regula o mercado de trabalho do avulso. Pode-se dizer até mesmo que ocorreu uma certa polarização da qualificação na atividade portuária, pois se de um lado dotou a estiva de trabalhadores especializados, conforme seus dirigentes sindicais reforçam, por outro temos os trabalhadores do Bloco, trabalhadores multifuncionais, considerados semiqualificados, pois assumem fainas e funções mais braçais nas operações portuárias.

A automação portuária também pode ser um fator para a polarização das qualificações no setor portuário de Paranaguá, pois gerou-se a necessidade de força de trabalho especializada para operação de equipamentos, e de outros trabalhadores multifuncionais que, na realidade, se caracterizam como força de trabalho supletiva. A isto se pode atentar para o que Salerno (1999) chamou de dificuldade em se distinguir um eixo entre trabalhador multifuncional e multiqualificado. No trabalho portuário, essa distinção se verifica entre trabalho especializado versus multifuncional, que no primeiro caso se caracteriza pela incorporação de habilidades e competências cognitivas especializadas, e no segundo caso considera o acúmulo de funções e de tarefas aditivas, além de uma maior intensificação do trabalho

\footnotetext{
${ }^{9}$ Trata-se de um tipo específico de movimentação de carga ou atividade no navio.
} 


\section{Considerações finais}

As reflexões apresentadas neste texto indicam que o resultado da extinção do controle dos trabalhadores, através de suas entidades sindicais, sobre a intermediação de sua força de trabalho avulsa, não só reforçou um controle mais direto do capital sobre a regulação da gestão da força de trabalho destas categorias de trabalhadores, mas também afetou a natureza da qualificação, que se dava tradicionalmente no cotidiano do trabalho portuário, aquela qualificação apoiada na noção do ofício, na empiria da aprendizagem mútua e nas relações de companheirismo entre profissionais. Além disso, a nova regulação da gestão da força de trabalho avulsa demandou um novo perfil de TPA, multifuncional e certificado.

Num contexto marcado por modificações profundas nas relações de trabalho, e principalmente nas mudanças dos conteúdos das operações portuárias, a competência certificada passa a ser um ponto central na discussão, pois é através desta que as categorias de avulsos podem se manter no mercado de trabalho e obter ganhos salariais maiores. Não seria exagero dizer que se trata da reelaboração desta qualificação feita pelo TPA, o qual se utiliza desta como meio de estratégia de permanência nas atividades do trabalho portuário, que cada vez mais são automatizadas e restringem os postos de trabalho, e que dependem cada vez menos de força de trabalho manual avulsa no processo de trabalho.

A regulação da gestão da força de trabalho impõe aos trabalhadores a qualificação certificada, e estes se sentem compelidos a se qualificar para continuar a executar suas funções profissionais. No entanto, não fornece o mínimo respaldo para que este trabalhador se qualifique adequadamente. O sistema impõe esta condição para o TPA permanecer no mercado de trabalho, mas, por outro lado, a qualificação ofertada pelo PREPOM - tanto qualitativamente em termos de material didático, que são deficitários, como quantitativamente, em relação ao número de vagas ofertadas, que são ínfimas - não dá as condições necessárias para estes trabalhadores fazerem frente as demandas exigidas para eles mesmos. O fator positivo disso reside no papel do instrutor dos cursos que também são TPAs, e por isso sabem das dificuldades encontradas pelos seus companheiros no cotidiano do trabalho. Estes instrutores estivadores, que tem a mesma linguagem e aproximação da realidade do cotidiano do trabalho portuário, se esforçam para suprir a lacuna dos materiais didáticos dos cursos do PREPOM, que são totalmente dissociados da realidade da prática do TPA. Estes TPAs instrutores não deixam de ser propagadores dos novos conhecimentos necessários para as demandas impositivas da regulação da gestão da força de trabalho.

Há o discurso oficial da qualificação do TPA, há o controle da regulação da força de trabalho através desta, há a exigência da individualização do TPA para buscar sua própria qualificação, há a evolução da automação e das tecnologias nos processos da operação portuária. Todos esses componentes, sem dúvida, criam controles da força de trabalho avulsa. Mas se percebeu nas falas dos entrevistados que há, a partir disso tudo, a reelaboração das regras do jogo como estratégia de enfrentamento dos TPAs para 


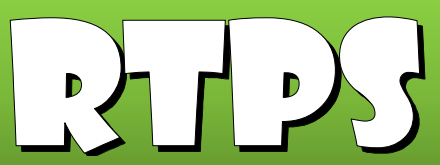

Revista trabalho, Política e Sociedade

permanecerem no mercado de trabalho, diante de um contexto em que as estratégias do capital vêm a cada momento buscando aumentar seu controle sobre a classe trabalhadora

\section{Referências}

BRASIL. Lei n. 8.630 de 25 de fevereiro de 1993. Dispõe sobre o regime jurídico da exploração dos portos organizados e das instalações portuárias e dá outras providências. Disponível em: https://www2.camara.leg.br/legin/fed/lei/1993/lei-8630-25-fevereiro1993-363250-publicacaooriginal-1-pl.html. Acesso em: 01 mar. 2020.

BRASIL. Lei No 11.632, de 27 de dezembro de 2007. Altera o inciso I do caput do art. 44, da Lei $n^{\circ}$ 9.394, de 20 de dezembro de 1996. Brasília (DF): 2007. Disponível em: http://www.planalto.gov.br/ccivil 03/ Ato2007-2010/2007/Lei/L11632.htm , acesso em 17/05/2020.

BRASIL. Lei $\mathbf{n}^{\circ} \mathbf{1 2 . 8 1 5}$, de 5 de junho de 2013. Dispõe sobre a exploração direta e indireta pela União de portos e instalações portuárias e sobre as atividades desempenhadas pelos operadores portuários; altera as Leis nº 5.025 , de 10 de junho de 1966, 10.233, de 5 de junho de 2001, 10.683, de 28 de maio de 2003, 9.719, de 27 de novembro de 1998, e 8.213, de 24 de julho de 1991; revoga as Leis $n^{\circ}$ s 8.630, de 25 de fevereiro de 1993, e 11.610, de 12 de dezembro de 2007, e dispositivos das Leis n's 11.314, de 3 de julho de 2006, e 11.518, de 5 de setembro de 2007; e dá outras providências. Brasília (DF): 2013. Disponível em: http://www.planalto.gov.br/ccivil 03/ Ato2011-2014/2013/Lei/L12815.htm , acesso em $17 / 05 / 2020$.

BRASIL. Lei $\mathbf{n}^{\circ}$ 9.394, de 20 de dezembro de 1996. Estabelece as diretrizes e bases da educação nacional. Brasília (DF): Disponível em: http://www.planalto.gov.br/ccivil 03/leis/19394.htm, acesso em 17/05/2020.

CARVALHO, Francisco Edivar. Trabalho portuário avulso: antes e depois da Lei de Modernização dos Portos. São Paulo: LTr, 2005.

DIEGUÉZ, Carla Regina Mota Alonso. A masculinidade do trabalhador portuário: novas questões em tempos de automação. In: FAZENDO GÊNERO 9, Florianópolis, 2010. Fazendo Gênero 9: Diásporas, Diversidades, Deslocamentos: Anais eletrônicos. Florianópolis: Editora da UFSC, 2010. p.1-9.

DIEGUÉZ, Carla Regina Mota Alonso. De OGMO (Operário Gestor de Mão-de-Obra) para OGMO (Órgão Gestor de Mão-de-Obra): modernização e cultura do trabalho no porto de Santos. São Paulo, 2007. 149 f. Dissertação (Mestrado em Sociologia) - Faculdade de Filosofia, Letras e Ciências Humanas, Universidade de São Paulo - USP.

DIEGUÉZ, Carla Regina Mota Alonso. Trabalho à deriva: contradição e ambiguidades nas lutas e percepções dos estivadores de Santos (1993- 2013). Campinas (SP), 2014. 347 f. Tese (Doutorado em Ciências Sociais) - Instituto de Filosofia e Ciências Humanas, Universidade Estadual de Campinas - UNICAMP.

DPC - DIRETORIA DE PORTOS E COSTAS. Normas da autoridade marítima para o ensino profissional marítimo, volume II: Portuários e Atividades Correlatas, NORMAM-32/DPC. Rio de Janeiro: DPC, 2017. 
DPC - DIRETORIA DE PORTOS E COSTAS. Fundo de Desenvolvimento do Ensino Profissional Marítimo: Relatório de Gestão. Rio de Janeiro: DPC, 2008.

DPC - DIRETORIA DE PORTOS E COSTAS. Normas da autoridade marítima para o ensino profissional marítimo, volume II: Portuários e Atividades Correlatas, NORMAM-30/DPC. Rio de Janeiro: DPC, 2012.

FIDALGO, Fernando. A Formação profissional negociada: França e Brasil, anos 90. São Paulo: A. Garibaldi, 1999.

FRIEDMANN, Georges. O trabalho em migalhas. $2^{a}$ ed. São Paulo: Perspectiva, 1964.

NAVILLE, Pierre. Essai sur la qualification du travail. Paris: Librairie Marcel Eiviére et Cie, 1956.

NETO, Arnaldo Bastos Santos; VENTILARI, Paulo Sérgio Xavier. O trabalho portuário e a modernização dos portos. Curitiba: Juruá, 2004.

PAUL, Norberto Luiz de França; FREDDO, Antonio Carlos. Questões sobre a multifuncionalidade nas operações portuárias em Santos. EGesta, Santos, Universidade Católica de Santos, v. 5, n. 3, p. 149-168, jul-set 2009.

PINTO, Cristiano Paixão Araújo; FLEURY, Ronaldo Curado. A modernização dos portos e as relações de trabalho no Brasil. Porto Alegre: Síntese, 2004.

QUEIRÓZ, Maria de Fátima Ferreira; GERALDO, Juliana Varela. O trabalho portuário até 1970: contexto internacional e nacional. In: QUEIRÓZ, Maria de Fátima Ferreira; MACHIN, Rosana; COUTO, Márcia Teresa (orgs.). Porto de Santos: Saúde e Trabalho em Tempos de Modernização. São Paulo: Fap-Unifesp, 2015. P. 33-48.

RAMOS, Marise Nogueira. A pedagogia das competências: autonomia ou adaptação? $3^{a}$ ed. São Paulo: Cortez, 2006.

SAAD, Eduardo Gabriel (Org.). CLT, Consolidação das Leis do Trabalho: comentada. $37^{a}$ ed. São Paulo: LTR, 2004.

SALERNO, Mario Sérgio. Trabalho e organização na empresa industrial integrada e flexível. In: FERRETTI, Celso João et al (Orgs.). Novas tecnologias, trabalho e educação: um debate multidisciplinar. 5.ed. Petrópolis: Vozes, 1999. P. 54-76.

SARTI, Ingrid. Porto vermelho: os estivadores santistas no sindicato e na política. Rio de Janeiro: Paz e Terra, 1981.

SILVA, Fernando Teixeira da. A carga e a culpa: os operários das Docas de Santos - direitos e cultura de solidariedade 1937-1968. São Paulo: Hucitec, 1995.

SILVA, Fernando Teixeira da. Operários sem patrões: da Barcelona à Moscou brasileira (trabalho e movimento operário em Santos no entreguerras). Campinas (SP): 2000. $494 \mathrm{f}$. Tese (Doutorado em História) - Instituto de Filosofia e Ciências Humanas, Universidade Estadual de Campinas - UNICAMP.

TARTUCE, Gisela Lobo Baptista Pereira. Algumas reflexões sobre a qualificação do trabalho a partir da sociologia francesa do pós-guerra. Educação \&. Sociedade. Campinas, v. 25, n. 87, p. 353-382, mai./ago. 2004a. Disponível em: http://www.cedes.unicamp.br. Acesso em: 11 fev. 2020. 
TARTUCE, Gisela Lobo Baptista Pereira. O que há de novo no debate da "qualificação do trabalho"? Reflexões sobre o conceito com base nas obras de Georges Friedmann e Pierre Naville. São Paulo: 2002. 231 f. Dissertação (Mestrado em Sociologia) - Faculdade de Filosofia, Letras e Ciências Humanas, Universidade de São Paulo - USP.

TARTUCE, Gisela Lobo Baptista Pereira. Pierre Naville e os estudos sobre a automação na França do Pós-guerra. Política \& Trabalho, João Pessoa, n. 21, p. 81-104, out. 2004b.

TRABALHADORES portuários concluíram curso de $1^{\circ}$ grau. Informativo do Órgão Gestor de Mão-de-Obra do Paraná, Paranaguá, n.18, p.5, nov/dez. 2000.

\title{
Informações sobre os autores:
}

\section{Mario Lopes Amorim}

Doutor em Educação pela Universidade de São Paulo (USP). Atua como professor da Universidade Tecnológica Federal do Paraná (UTFPR), onde integra o quadro docente do Programa de Pós-Graduação em Tecnologia e Sociedade (PPGTS).

ORCID iD: http://orcid.org/0000-0001-6610-7909

E-mail: marioamorim@utfpr.edu.br

\section{Luceli Gomes da Silva}

Doutoranda em Sociologia pela Universidade Federal do Paraná (UFPR), Mestra em Tecnologia e Sociedade pela Universidade Tecnológica Federal do Paraná (UTFPR).

ORCID iD: http://orcid.org/0000-0002-3663-5476

E-mail: luceligs@gmail.com

\author{
Submetido em: $13 / 03 / 2020$ \\ Aprovado em: $\quad 28 / 04 / 2020$
}

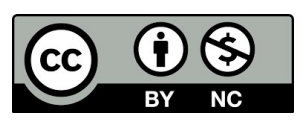

Esta obra está licenciada com uma Licença 